\title{
Cultural Studies of Tibetan Packaging of Handicraft Products
}

\author{
Zhaoying XIANG \\ Department of Fine Art \\ Sichuan University for Nationalities \\ Kangding,626001 China
}

\begin{abstract}
Tibetan handicraft products are beautifully designed with meticulous workmanship, unique cultural patterns. Tibetan cultural handicraft product packaging is showing the cultural essence of the Tibetan people, culture and the arts and crafts are created between cultural factors and cultural relations. Tibetan handicraft product packaging is exploring the origin of culture. Tibetan handicraft products and packaging are considered to have irreplaceable cultural relations, which contacts meta analysis of factors in Tibetan culture and handicraft product packaging and cultural needs and cultural consumption and Tibetan handicraft products. Tibetan handicrafts made cultural development of different product packaging differences in the modern context of cultural development orientation.
\end{abstract}

Keywords- Tibetan; Crafts; Product Packaging; Packaging Culture

\section{INTRODUCTION}

Tibetan handicraft products are distinctive, beautifully designed with meticulous workmanship, unique geographical environment, which are closely related to the social and cultural life, with a distinctive artistic value and practical value, the human material and spiritual treasure. It is one of the big family of the Chinese nation handicraft products and it has significant cultural significance. It is a member of its packaging, especially with a heavy sense of history and culture, the existence of a clear sense of culture, technology direction and a strong spiritual power source for the development of Tibetan culture, and it has made a great contribution. Tibetan handicrafts were produced from the Stone Age into the liberation of a very long period of time, despite the constraints, Tibetan handicrafts development has been part of cultural values, underprivileged artisans, etc. But, because of the changing times, the rapid development of economic and cultural liberation Tibetan has innovation and other reasons, the Tibetan handicraft culture shock through the world and continue to develop. [1] The existence of its unique local conditions and cultural significance of handicraft products for Tibetan cultural exploration package provides historical and actual research vision ideas. Discussion on Tibetan handicraft products, packaging and cultural origin, is necessary to explore the differences between traditional and modern handicraft products handicraft products. We must understand the relationship between material culture and non-material culture, which needs to clarify the characteristics of Tibetan handicrafts packaging art, crafts, and cultural needs through underlying the development of the relationship between power consumption and cultural point of view of packaging culture. Packaging as a relatively independent cultural form, is together with the process of the product itself into the consumer space from the circulation, in fact, it continues to spread a culture process. [2] it also shows that, from a historical perspective, the development of Tibetan handicrafts in different periods of history show blots of historical development, to provide reference for cultural development.

\section{CULTURE OF ORIGIN}

Study the origin, the element (start, a fundamental element that is the root cause and the factors, factor) better reflects the origin of the elements of the most powerful resource as a processing element. "Wenxindiaolong - Yuan Tao": "Humanities element, Zhao is from Tai Chi", means the beginning. "On balance - right to make": "" change "the universe," The War Period" of the element, Young is mysterious, it is also uneven", means the fundamental roots. Since the 7 th century Tibetan Buddhist art, Tibetan handicraft products for design and aesthetic laid a solid foundation. [3] as for the Tibetan handicraft between traditional and modern development, there is no clear distinction between the stage, only to see the historical process, it is with the Tibetan cultural exchanges with neighboring ethnic Tibetan cultural fusion, with varying degrees of cultural acculturation happened, mutual Effect of process. Throughout the development of Tibetan art, from the Stone Age pottery techniques, rock, bone artifacts and architectural form to the formation of small states during the local art, Tibetan art began in Tubo period, Tibetan art Guge changed. It has done through Sakya Tibetan art of the period development. In Phagmodrupa Dynasty period Tibetan art flourished, Ganden Phodrang mature and contemporary Tibetan art innovation situation during the Tibetan art, reflects the Tibetan arts and crafts from cultural origins to modern Tibetan handicraft products, the packaging innovation of culture history is under development context. [4] Tibetan handicraft development of spiritual and cultural history does not appear in a major turning point, but only on innovative materials and techniques and other factors 
unrelated to the spirit in the development of national culture, such as traditional and new Thangka traditional woodcuts and wood arts Cheung Pakistan.

Tibetan handicraft products have effective dissemination of culture through the packaging, and they are highly recognizable. Tibetan handicrafts and cultural factors included: Tibetan painting (such as hand-painted thangka), metal crafts, weaving, clothing technology, mask technology, pottery craft, paper craft, carving and other such instruments, furniture making, Tibetan incense and other technology. Therefore, Tibetan cultural arts and crafts package source factor need to be made, with the following characteristics: 1 idea origin. The most important source of Tibetan handicraft product packaging is the Tibetan culture, society and culture from religion and beliefs, Tibetan Bon religion there and Tibetan Buddhism and folk beliefs. Elements are: mythology, history, character designs, printing Buddhist scriptures, packaging, packaging different sects doctrine books, culture, medicine, books and other packaging, Buddha and other religious leaders, figures of Atlas packaging. 2. color source: The most respected Tibetan colors are white, blue, red, yellow, green, but not all. You can find basic color elements from traditionally Tibetan handicrafts packaging and colorful. Different color sense is not the same, as white represents clouds, red for fire, yellow for the land, green represents water. At the same time, there is the same color on different occasions to express the significance that is not the same as having a sense of orientation of Buddhism white Vajrasattva hammer bits representing the East, especially in Tibetan; white character mask refers to male. There are complicated color handling and color abstract expressionism methods. 3 pattern source. Tibetan patterns are achievements of civilization in the process of creating the social and historical development and heritage through the generations. [5] the history of Tibetan pattern formed a content-rich, colorful, wide range of expression, the performance characteristics of various forms. Through cultural heritage, Tibetan pattern has emerged diverse expressions, common expressions such as symmetrical patterns, but on the basis of symmetry, there are changes; there is full composition; there are flowers and birds scenery composition. 4 Economic source: Tibetan handicrafts from an economic point of view, only one will be very expensive production materials, the use of rare mineral pigments, handmade Tibetan paper, the use of gold and silver, agate, pearls, turquoise, red coral, bronze, so that Tibetan handicrafts packaging artistic level reached unprecedented heights. Especially during the Ganden Phodrang Tibetan handicrafts presents a new historical high, well-made, decorated with typical characteristics of applicability. In addition to the production of handicrafts temple worship, and ritual use, the remaining life of the product has the process of money value. For the Tibetan people, artisans brought to improve life. With modern industrial impact on the traditional handicraft production, the development of Tibetan handicrafts are also affected accordingly, from an economic perspective, Tibetan handicraft products and their packaging innovation research culture, yet cannot stop. 5 source of production process. Traditional Tibetan handicraft products, packaging production needs makers to have spiritual power, physical suffering energy, innovation and energy to have a sophisticated production standards in this area. Modern Tibetan handicraft products packaging production can aid the development of modern industrial machines to complete. But tourists may feel far from the level of craftsmanship and traditional handicraft products compared, there has been a lot of dating that cannot match, and in Tibetan handicraft products purchase channels, most of the goods from Nepal, India, few domestic producers are specializing in the production of Tibetan handicraft products. 6 performances source. Show is to demonstrate and intuitive understanding of Tibetan culture and the arts. Tibetan handicraft production chain, handmade clothing and other performances have performances integrate cultural nature of the packaging that will help us to understand and develop the cultural needs and research in the field of culture Tibetan handicraft products, forming a unique package of cultural aesthetic way. 7 decorative element. Integration significance of this decorative element lies in Tibetan handicraft products in the Tibetan architecture, clothing, towers and other vector art packaging, for various historical periods of Tibetan social and cultural product packaging. Such as weaving, stone, wood, ceramics, etc., that can be called art deco packaging culture. 8 cultural needs and consumer element. Cultural needs and cultural consumption are complementary, Tibetan handicraft products as a carrier of Tibetan art is reflecting the producers, the audience or consumer demand on Tibetan culture and cultural consumption is selective. The selectivity required for effective organization by the meta-factors after all, is the need to understand Tibetan handicraft art through contact. It is the ways to enjoy consumption to meet consumer demand for the audience or carriers such as Thangka Tibetan culture, gold and silver. Reasonable Tibetan handicraft products packaging and packaging has a very important role in the future of the Tibetan cultural orientation package.

\section{PACKAGES OF CUltural ORIENTATION}

Tibetan handicraft products as a carrier of culture have an irreplaceable position in Tibetan daily life, tourism industry development, economic development, cultural and artistic heritage and other aspects. By analyzing the characteristics of Tibetan culture and handicraft finishing packaging products, element factors for the development of packaging positioning provides a good support. Packing culture is with merchandise attributes. But at the same package, it must have a strong cultural recognition to meet the spiritual, aesthetic, and the needs of consumers. But Tibetan handicraft products and packaging, but there are some differences in cultural tourism products in other regions, which can not reflect the unique cultural background. But, on the whole, there is a strong national characteristics. However, we can see that when we went to the store of handicraft products in Kangding or in Jiuzhaigou, the handicraft products are almost identical. In other words, strong ethnic identification, and regional recognition are very low, or there is no difference. This can be said for tourists or those who experience it, there is no larger significance. Therefore, it 
proposed packaging culture of the times, the difference between the concepts of Tibetan handicraft products such as the positioning is of great significance.

\section{A. Real Demand Location and Cultural Heritage}

Reality demands on Tibetan handicraft product packaging are mainly reflected in the cultural audience, and cultural needs of consumers looking for fresh and different experiences in the modern information society. It mainly refers to the production of cultural heritage, the production process that have disappeared or are disappearing are the needs of modern society, while it cannot lose even more development and innovation. Ace Travel Channel program "Departed" Together with Zhu Zheqin's "world to see ethnic handicrafts searching journey," during the inspection process, you can see that very few artists have the heritage crafts, and many popular industries in the past have been severely impacted in modern culture. If we cannot combine modern society and cultural heritage, which will not closely reflect the theme of "carry forward the national art, the continuation of the Chinese Culture" that China's fourth Cultural Heritage Day raised.

Positioning of the main demands need heritage demand, development needs and the need of times. Travel status at this stage in China's social and cultural life is very important, if we do not give the audience a real, traditional, cultural heritage tourism project, so the audience would be against to the desire for cultural needs. Tibetan handicraft products packaging and cultural need audience to convey accurate positioning.

\section{B. Positioning Differences of Packaging Culture}

The main areas of regional differences reflect in fine differences and meeting the cultural needs of the audience's enthusiasm differences. Today for tourism, people in addition to seeing outside of landscapes, are more interested in folk customs. If we focus only on its original character, at the expense of product packaging, that will make our product packaging showing no difference. [6] If only to divide ethnic differences, this is a very rough approach, as mentioned above in Kangding and Jiuzhaigou, cultural origin is insignificant, but it has very different geographical characteristics that we cannot confuse. The geographical and cultural characteristics, the environment, material aspects of handicraft products and handicraft production environment vary, and this difference is the most essential meaning for the packaging of cultural differences in positioning.

\section{Differences Positioning of Packaging Artistic}

To understand the Artistic and cultural differences requires understand, conclude and apply positioning packaging folk culture context, art and color certain geographical knowledge. [7] What mentioned here refers to a certain geographical area that has a certain cultural differences; it cannot simply be summed up as the geographical administrative divisions. It needs to conclude the characteristics such as design element, color source, decorative element, and performing source factors. Difference reflected in a certain area, the environment, the arts and other differences, could better create a Tibetan handicraft products of different artistic differences. But this should not be an excuse for a regional protection, although modern society is shared with pluralistic culture, however, important differences should always be an integral element of cultural development.

\section{CONCLUSIONS}

Tibetan handicraft products must have the distinct cultural differences in order to make the positioning of different ages, different audiences. The different cultural contexts have a strong driving force for development, in order to make Tibetan handicrafts and cultural heritage has a strong life force. Tibetan handicraft culture on the basis of product packaging, such as Yuan has ideological factors, we can find a clearer social development, effective thinking its future development, provide a space for the development of Tibetan culture package. You can see that the intangible cultural heritage protection and cultural heritage of the Tibetan package inject new impetus into the development. Much attention should be taken at times to seize the opportunity to bring the Tibetan handicraft products, packaging and cultural mentioned to cultural development agenda, by holding packed cultural competitions, cultural breakdown product positioning, to establish a packaging culture base, the establishment of people packed cultural heritage training, etc., to improve the quality of modern Tibetan culture package.

\section{Acknowledgements}

Fund: Sichuan Provincial Education Department 2013 annual general funded research project (13SB0188).

\section{References:}

[1] Zha Xia. Tibetan Traditional Handicrafts research [M] China Tibetology Publishing House, Beijing .2005: 1-55.

[2] Lou Ruixue. Study packed cultural orientation [J] China's packaging industry, 1997 (4): 45.

[3] Wu Mingti. Han history of Tibetan arts and crafts exchange. [M] China Tibetology Publishing House, Beijing .2007.

[4] Gesang Yixi. Art history. Tibetan [M]. Sichuan Nationalities Publishing House, Chengdu .2007.

[5] Zhang Xiaobing. Charm national arts culture - cultural connotation of Tibetan art pattern [J] Grand Art, 2009 (1): 170.

[6] Jiang Jiawei. Packaging design from minority culture to tourism products [J] Popular Literature, 2009 (16): 132.

[7] Zhang Qi and other. Study of native folk art packaging design factor [J] Packaging Engineering, 2012 (5): 3. 